\title{
Yangın Güvenliği Ve Tahliye Yönetimi
}

\footnotetext{
${ }^{* 1}$ Bülent AÇIL , ${ }^{2}$ Orhan ODUNCU, ${ }^{3}$ Tayfun TURNALI,${ }^{4}$ Selçuk KÖMCÜ, ${ }^{5}$ Tuğrul SOYSAL, ${ }^{6}$ Gökhan COŞKUN, ${ }^{7}$ Hakan Serhad SOYHAN 1,2,3,4,5 Sakarya Üniversitesi Yangın güvenliği ve Yanma ABD

${ }^{6,7}$ Sakarya Üniversitesi Makina Mühendisliği ve Yangın Araştırma ve Uygulama Merkezi Serdivan/Sakarya
}

\section{Özet}

\begin{abstract}
Alınan tüm tedbirlere rağmen yangın vakalarının meydana getirdiği can ve mal kayıpları gün geçtikçe artmakta her yangın olayından sonra bu gibi felaketlerin önlenebilirliğine yönelik tartışmalar güncelliğini koruyarak süregelmektedir. Özellikle binalarda yangın güvenliğinin yetersizliği ve etkin tahliye yöntemlerinin organizasyonel boyuttaki problemleri kamuoyu nezdinde tartışma konusu olmaya devam etmektedir. Yangın güvenliğinin birincil önceliği olan insan hayatının korunmasına yönelik tedbirler toplu yaşam alanlarında ve özellikle yüksek yapılarda öneminini her geçen gün arttırmaktadır. Alışveriş merkezleri, spor arenaları, konser salonları gibi yüksek riskli yerler günümüzün modern yangın teknolojileri ile donatılmaktadır. Şüphesiz bu alanlarda modern cihazların yanı sıra etkin ve güvenli tahliye ve kurtarma planlarıda sürekli olarak gözden geçirilmeli ve pratikleri periyodik olarak yapılmalıdır. Bu çalışmada yapılarda olası bir yangın durumunda tahliye süresinin hesaplanması ve tahliyeye etki etken faktörler incelenmiştir.
\end{abstract}

Anahtar Kelimeler: Yangın, Yangın güvenliği, Tahliye yönetimi

\section{Giriş :}

İnsanı koruma yangın güvenliği konseptinin birinci önceliğidir. Yangın durumunda kişisel korumayı etkileyen en temel faktör bir binanın zamanında tahliyesini sağlamaktır. Bu bağlamda, tahliye ile ilgili birçok yasa, direktif ve yönetmeliğin çoğu zaman çok basitleştirilmiş uygulama kurallarına dayanmaktadır.

İnsanların toplu olarak bulunduğu binalar insan yoğunluğu nedeni ile daha fazla önem arz etmektedir. Özellikle yüksek katlı binalar, alışveriş merkezleri, spor arenaları, konser salonları vb. yerleri bu sınıfa örnek verebiliriz. Büyük insan yığınları arasında kişinin yangın gibi bir felaketten kendini koruması ve kurtarması o bina ile ilgili tahliye planının ve fiziksel ortamın sorunsuz olmasına bağlıdır. Bu yüzden tahliye ve kurtarma faaliyetlerinin felaket öncesinde planlanması ve boyutlandırılması daha da önemli hale gelmektedir. Çünkü tahliye işlemi şekil 1'de ki resimde izah

*Sorumlu Yazar: Adres: Fen Bilimleri Enstitüsü, Yangın güvenliği ve Yanma ABD, Sakarya Universitesi, 54187, Sakarya Türkiye. E-mail address: bulent@andem.net, Telefon: +905334861296 
edildiği üzere bütün bir tedbir sürecinin bir kısmıdır ve sürecin bütün parçaları ile etkileşim halindedir.

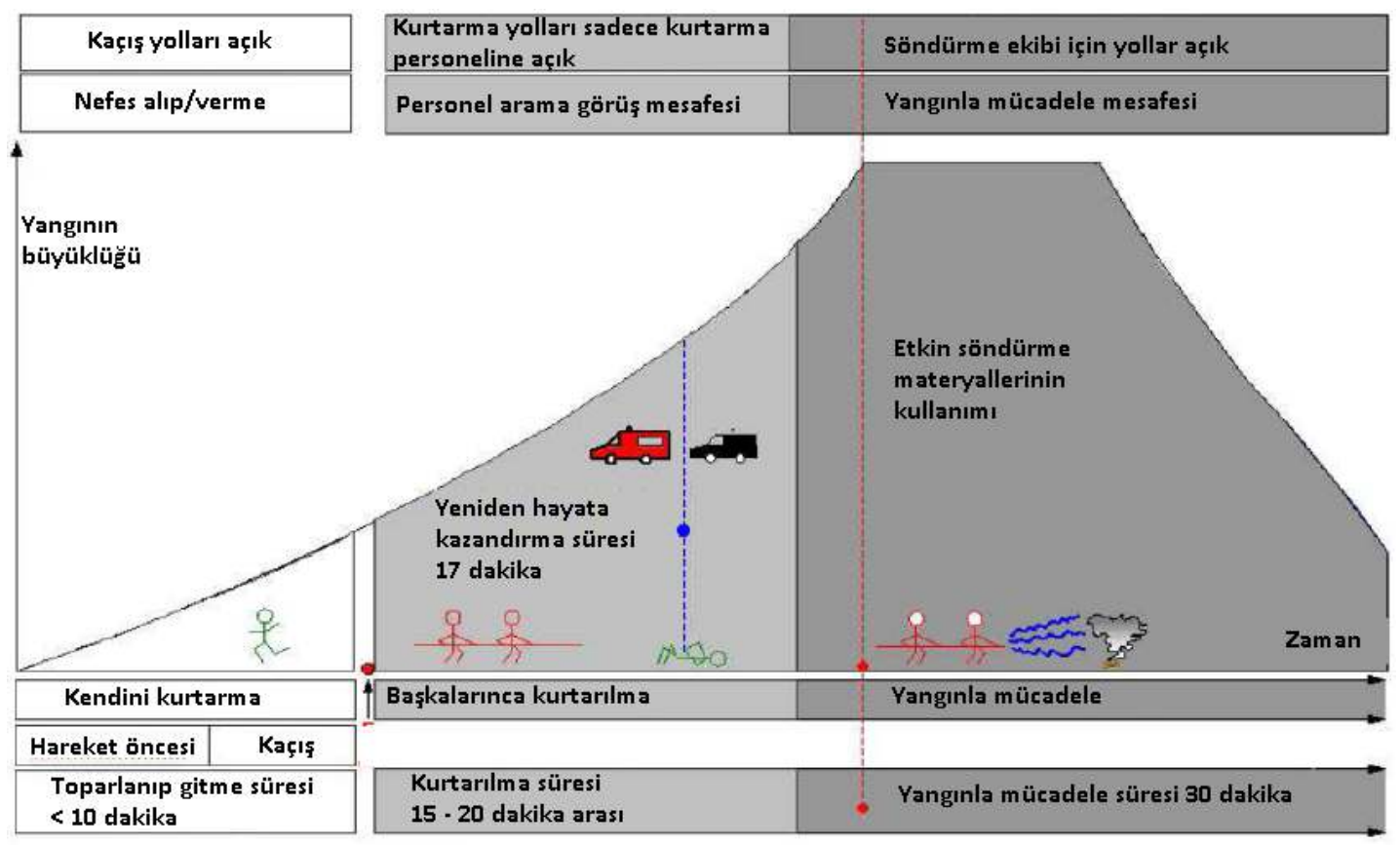

Şekil 1:Tahliye Yönetimi ve Yangın Süreci

Bu nedenle bütün modern ülkelerde olduğu gibi Ülkemizde de binanın büyüklüğüne ve içerisinde dolaşacak insan çokluğuna bağlı olarak acil çıkışların sayısı ve genişliği ile kurtarma yollarının uzunluğu kanun ve yönetmeliklerle düzenlenmiş ve belirli standartlar getirilmiştir. Elbette ki tahliye ve kurtarma zamanına ilişkin bir yasal düzenlemenin yapılması beklenemez. Ama genel geçerli kural tahliye ve kurtarma planlamasının en zor şartlar dikkate alınarak yapılmasıdır. Bir alışveriş merkezi için örneğin en optimal tahliye planlama zamanı elbette o merkezin en yoğun olduğu saatler olacaktır. Çünkü hem yangın riskinin en fazla olduğu hem de zararın en çok olabileceği zaman dilimi insanların en kalabalık olduğu andır. Bu zaman dilimi dikkate alınarak mühendislik ölçüsünde birçok tahliye süresi hesaplamaları yapılabilir.

$\mathrm{Bu}$ hesaplamalarda tahliye süresinin çok sayıda faktöre bağlı olduğu göz önünde bulundurulmaktadır. Ama genel itibari ile merkezde insan olmak üzere insan, bina, çevre ve tedbirler arasında sıkı bir ilişki vardır. Örneğin tahliye yapılan binanın yoğunluğu, içinde bulunan insanların profili ve mevsim şartları bu süreci etkileyen faktörlerin başında gelmektedir. 


\section{Yangın Güvenliği Konsepti}

Yangın güvenliğini dar manada canlıları, binaları, tesisatları ve hertürlü eşyaları yangının zararlarından koruma olarak tanımlanabilir. Yangın güvenliği kapsayıcı bir konsepttir ve tahliye güvenliği bu konseptin bir parçasıdır. Bu kapsayıcı konsept yapısal teknik ve yönetimsel tedbirleri içerisinde barındıran çok geniş bir spektrumdur [1].

\subsection{Kişi Yoğunluğu :}

Fizik kuralları içerisinde yoğunluk (density) birim hacimdeki (volüme) madde miktarı (mass) olarak tarif edilir. Hesaplama formülü $\mathrm{d}=\mathrm{m} / \mathrm{v}$ şeklindedir. Predtetschenski ve Milinski tahliye anındaki insan yoğunluğunu hesaplarken aşağıdaki formülü kullanmıştır

$$
\begin{aligned}
& D=\frac{\sum f}{b * l}\left[\frac{m^{2}}{m^{2}}\right] \\
& \sum f=\sum P * f^{*}
\end{aligned}
$$

D : Tahliye olan kişi yoğunluğu

P : Tahliye olan kişi sayısı

b : Tahliye koridor genişliği

1 : Tahliye olunan koridor uzunluğu

f* : Bir kişilik tahmini alan

Elbette ki kişilerin değişken yapısı kesin sonuca giden bir formülasyön çok mümkün görünmemektedir. Ancak maksimum yoğunluğun belirlenmesi için kabul edilen husus vücudun düşey projeksiyonundan kaynaklanan elipsin, insanların akışının sıkıştırılmasında deformasyona uğramayacağıdır. Sonuç olarak, fiziksel olarak yoğunluk sınır değeri Dmax $=0,92$ olarak kabul edilmektedir [2]. 


\subsection{Tahliye}

Tahliyeyi "hem insanları ve hem de hayvanları tehlikeli bir alandan, güvenli bir alana örgütlü bir şekilde ulaştırma" olarak tanımlanmaktadır [3]. Tehlikeden kasıt hayatın, vücut bütünlüğünün, eşyaların ve çevrenin tehdit altında olmasıdır. Güvenli alan ise tehlikeden arındırılmış bölgedir [4]. Bu süreç hem uzun vadeli hem de kısa vadeli olabilir. Öncelikli olarak "tehlike bölgesini terk etme kararı" alınması gerekiyor. Yangın tehlikesi kısa ve yıkıcı olduğu için yangına konu tahliye süreçleri çok kısa vadelidir [5].

Werner ve Schmutz dört farklı tahliye tipi tanımlamaktadır:

- Acil Tahliye: Yakın (kaçınılmaz) tehdit durumundan yapılan hızlı tahliyedir.

- Kontrollü Tahliye: Belirli tehdit türleri için dolaylı olarak sınıflandırılır veya doğrudan yaşamı tehdit etmeyen tehlikelere karşı düzenli bir şekilde uygulanır.

- Kısmı Tahliye: Bu durumda, sadece tehlikeli bölgedeki insanlar tahliye edilir.

- Bina İçi Yer Değişimi: Eğer çıkış yolları kapalı ise personel tehlike altındaki bölge içerisinde daha az tehlikeli kabul edilen alana kaydırılır. ${ }^{*}$

Bütün bu tasniflere ilave olarak Müller ayrı bir konsepti de tahliye içerisinde saymaktadır. O da insanların bulundukları bölge diğerlerinden daha güvenli ise orada kalmalarını sağlamak (stay put) ve çevrelerini daha güvenli hale getirmektir.

Yukarıdaki tanımlara bir sınırlama olarak kaçışı irdeleyebiliriz. Kaçış tehlike korkusu nedeni ile insanların şuursuz, düzensiz, örgütsüz ve kendiliğinden bir kitle psikolojisi ile belirli bir yöne doğru sürüklenmesidir. Patlama şeklindeki baskın yangınlarda ilk reaksiyonu tahliyeden ziyade panik halinde kaçış olarak görebiliriz.

Bu nedenledir ki Binaların Yangından Korunması Hakkında Yönetmeliğin birçok yerinde tahliye ve kaçış kelimeleri birbirlerini ikame edecek şekilde kullanılmaktadır.

* Bu husus Binaların Yangından Korunması Hakkında Yönetmelik içerisinde "yatay tahliye alanı" olarak tanımlanmıştır. 


\section{Yasal Düzenlemeler}

7126 say1lı Sivil Savunma Kanunu'nun ek 9 uncu maddesine göre, Bakanlar Kurulu'nca 27/11/2007 tarihinde kararlaştırılan 207/12937 karar sayılı "Binaların Yangından Korunması Hakkında Yönetmelik" tahliyeye ilişkin birçok düzenleme içermektedir. Yönetmeliğin tahliyeye ilişkin en önemli düzenlemesi “yangın tahliye projesi” hazırlanması zorunluluğudur. Bu projelerde kaçış yollarının, yangın merdivenlerinin, acil durum asansörlerinin, yangın dolaplarının, itfaiye su verme ve alma ağızlarının ve yangın pompalarının yerlerinin renkli olarak işaretlenmesi gerekmektedir (Madde 4). Konutlar hariç olmak üzere, yüksek yapılarda ve yapı inşaat alanı 5000 $\mathrm{m}^{2}$ 'den fazla olan yapılarda mimari projelerden ayrı olarak "yangın tahliye projesi" hazırlamak bir zorunluluktur. Diğer yapılarda ise, mimari projelerde gösterilir. Projeler; ilgili belediye itfaiye birimlerinin uygun görüşü alındıktan sonra, belediye ve mücavir alan sınırları içerisinde belediyelerce, belediye ve mücavir alan sınırları dışında ise, valiliklerce onaylanarak uygulanır (Madde 6). Yine diğer önemli bir düzenleme binaların inşa halinde kullanıcıların binayı terk etmesine veya diğer yollarla kurtarılmasına imkân verecek şekilde yapılması gerektiğini hükme bağlamasıdır (Madde 20).

Yönetmelik tahliye konularını da içine alan bütün hükümlerin uygulanmasından yapı ruhsatı vermeye yetkili idareleri, yatırımcı kuruluşları, yapı sahiplerini, işveren veya temsilcilerini, tasarım ve uygulamada görevli mimar ve mühendisler ile uygulayıcı yüklenicileri ve imalatçıları, yapı yapılmasında ve kullanımında görev alan müşavir, danışman, proje kontrol, yapı denetimi ve işletme yetkililerinin tamamını görevli, yetkili ve sorumlu tutmuştur. Tabi yetki ve sorumluluklar yönetmelik hükümleri ile sınırlı değildir. Tahliye konusunu da içine alan acil durum planları çerçevesinde yapılan çok sayıda yasal düzenleme mevcuttur. Tüm iş ve işlemlerde başta iş güvenliği uzmanları olmak üzere geniş bir sorumluluk sahasından ve bütün bireylerin ortak çabasını gerektiren kolektif bir tedbir anlayışından bahsedebiliriz.

Yönetmeliğin 3. Kısmı bir bütün halinde tahliyeye ilişkin yasal düzenlemeler yapmıştır. Tahliye güvenliği (Madde 30) başta olmak üzere tahliye yolları (Madde 31), kaçış kapasitesi ve kaçış uzaklığı (Madde 32), kaçış yolu sayısı ve genişliği (Madde 33), yangın güvenlik holü (Madde 34), kaçış yollarının gerekleri (Madde 35), korunumlu iç kaçış koridorları ve geçitler (Madde 36) ile dış kaçış geçitleri (Madde 37) detaylı olarak düzenlenmiştir. 
Düzenlemeler içerisinde konumuz açısından en önemli hususlardan bir tanesi ek 5A'da listelenen “kullanıcı yükü katsayısı” ve ek 5B’de listelenen “çıkışlara götüren en uzun kaçış uzaklıkları ve birim genişlikleri” ile ilgili düzenlemelerdir.

\section{Tahliyeye Etki Eden Faktörler}

Tahliyeye temel olarak etki eden üç faktör vardır. Birincisi tahliyeye konu insan faktörüdür ki bu faktörü de kendi içerisinde etkileyen sürekli değişken birçok boyuttan söz edilebilir. İkinci önemli faktör binanın yapısal ve teknik özellikleridir. Bu faktörün analizi diğerlerine nazaran daha mümkündür ve teknoloji bu manada geniş bir perspektif sunmaktadır. Üçüncü ve son faktör yangın faktörüdür. Yangının çeşidi ve çapı özellikle tahliyeye etki eden en önemli unsurdur. Yoğun 1s1 ve duman örneğin tahliyeyi daha da zorlaştırabilmektedir.

\section{1. Ínsan Faktörü}

Bütün parametreler yangın anındaki insan faktörünü üç kategoride toplamaktadır:

- Tecrübe ve Bilinç Seviyesi: Kişinin yangın hakkındaki bilgisi ve tecrübesi yangın anındaki reaksiyonuna etki edecek birinci faktördür. Bilgi ve tecrübe alarm verildiği andan itibaren devreye girmekte ve kişiyi yönlendirmektedir.

- Fiziki Kabiliyet: Alarmları algılamada, insan yığınları arasında hareket edebilmede ve yön tayininde fiziki özellikler ön plana çıkmaktadır.

- Kişilerin Dağılımı: Bina içerisinde bulunan kişilerin sayısı ve dağılımı tahliye anında kişiler üzerinde etkilidir. Aşırı kalabalık veya çok az sayıda insan ve bunların bina içerisindeki dağılımı bütün bireyler üzerinde etkili olmaktadır.

Bu çerçevede yapılan birçok çalışma göstermiştir ki yangın anında insanların sadece \%10-15 arası bir kesimi çok rasyonel hareket etmektedir. \%70 gibi bir bölümü ise olayın şokuna girmesine rağmen, çabuk toparlanıp sürece pozitif katkı sunmaktadır. Geriye kalan \%10-15'lik dilim ise hareketleri kestirilemeyen grubu oluşturmaktadır [6].

\subsection{Genel Panik}

Panik genel olarak bir insanın düştüğü müşkül bir durumdan kurtulmak için göstermiş olduğu durdurulması güç sıra dışı reaksiyonel davranışlardır [7].Genel panik ise iletişim halindeki birçok insanın zor bir durum karşısında gösterdiği reaksiyoenl ve kolektif bir davranış biçimdir. Helbing 
ve ark. yapmış oldukları bilgisayar simülasyonu ile yangın anında panik faktörünü incelemişler ve şu sonuca varmışlardır. Bireysel ve kolektif davranışların optimal bileşimi en uygun yangından tahliye stratejisidir [8].

\subsection{Hareket Hozı}

Hız (v) tahliyede merkezi öneme sahiptir ve hız vektörünün miktarı ve yönü ile karakterize edilir. Tahliye anında kişinin hedefi kural gereği en yakın çıkışa güvenli bir şekilde ulaşmaktır. Tabi bu esnada insanlar oluşan duman ya da yoğunluk nedeni ile rotalarını başka çıkış kapılarına çevirmeleri olası bir durumdur. Tahliye anında kişileri yönlendirenler de olabilir ve bu da insanların rotalarını değiştirmelerine neden olabilir.

Tahliye yolunun açık olması durumunda hareket hızı normal seviyesine ulaşır. Bu durumda ortalama ölçülere sahip bir yetişkinin hareket hızı 1,2 m/s - 1,4 m/s olarak hesaplanır. Tabi bu hesaba ulaşılması binanın dizaynına ve kullanım amacına, kaçış yollarının çeşidine (düz yol, merdiven, yangın merdiveni vb.), insanların yoğunluğuna, tahliye olunan kişilerin fiziki özelliklerine ve psikolojik durumuna, yangının çeşidi ve büyüklüğüne bağlıdır [9].

\section{4.İtiyaç Duyulan Alan}

Tahliye anında ihtiyaç duyulan alan her bir bireye insan akımı esnasında lazım gelen hareket alanıdır. İhtiyaç duyulan toplam alan ise bütün bireylerin senkronize bir şekilde tahliye edilmelerine ihtiyaç duyulan bütün alanlar toplamıdır. Bu hesaplanırken insan vücudunun kapladığı alan dikkate alınır.

\subsection{Teknik Alt Yapı}

Teknik alt yapıyı yapısal ve donanımsal olarak iki başlık altında toplayabiliriz. Yapısal tedbirler bir taraftan güvenli kaçışı dizayn ederken diğer taraftan duman gibi çevresel faktörlerin etkisini minimize etmektedir. Yeterli genişlikte kaçış alanı, yeterli sayıda acil çıkış kapısı ve itfaiye ekiplerinin yanaşmasına imkân tanıyan yapısal tedbirler tahliyeyi kolaylaştırmaktadır. Diğer yapısal tedbir olan duman bacalarının en önemli fonksiyonu ise dumanın etkisini en aza indirerek tahliye üzerindeki olumsuz etkisini azaltmaktır. 


\subsection{Yangın Dumanı}

Yangın anında tahliye hızını en çok etkileyen çevresel faktör oluşan dumandır. Duman solunum almayı da güçleştirmekte ve hız performansını etkilemektedir. Çünkü dumanla beraber gelişen solunum yetmezliği baş dönmelerine, bilinç kayıplarına ve kusmalara sebebiyet vererek hareket hızını olumsuz şekilde etkilemektedir. Dumanla beraber yayılan ısı diğer önemli faktörlerden biridir. Isının şiddetine bağlı olarak oluşan yanıklar ya da tahliye anında kullanılan solunum cihazlarındaki deformasyonlar ilave olumsuz sonuçlar doğurabilmektedir. Duman toplumsal paniği de tetikleyebilecek bir faktördür. Rasyonel davranan insanlar dahi yoğun duman baskısı altında kırılmalar yaşayabilir ve paniğe kapılabilirler. Bu da normalde çok panik insanların oranını \%1015 'lerden çok yukarılara taşıyabilir ve tahliyeyi güçleştirebilir.

\section{Tahliye Süresi Hesaplama}

İnsanların yangın anında güvenli tahliyeleri konusunda iki yaklaşım vardır. Birincisi kanun metinlerinde ve standardizasyon çalışmalarında geçen tanımsal verilerdir. İkincisi ise mühendislik yaklaşımdır. Tanımsal yaklaşımı tamamlayıcı karaktere sahiptir. Bütün değişkenleri göz önüne alarak güvenli tahliye modellemesi yapmaktadır. Tahliye hesaplamalarını makroskopik ve mikroskopik modeller olmak üzere iki başlık altında da toplayabiliriz [10].

\subsection{Makroskobik Modeller}

Aynı zamanda hidrolik modeller olarak da adlandırılan makroskobik modellerde, insanların akışı olarak insanların hareketi sıkıştırılabilir bir gaz veya sıvı ile karşılaş̧ırılmaktadır. İnsanların akışı içindeki bireylerin hareket ve davranışları dikkate alınmaz. Hesaplama "elle" yapılır, bu nedenle bu hesaplama yöntemleri "el hesaplama yöntemleri" olarak da adlandırılır. Ampirik verilerden türetilmiş formülleri temel alırlar. Basit geometriler için hızlı sonuç verir. Makroskopik modeller grubunda, kapasite analizi ve dinamik akış modelleri ile ağ modelleri farklılaştırılabilir.

\subsection{Mikroskobik Modeller}

Makroskobik modellerin aksine, mikroskobik modeller, bireylerin hareketi ve etkileşimini de hesaba katar, bu nedenle modellere bireysel modeller olarak da değinilir. Her kişinin, kişisel 
davranı̧̧ını karakterize eden kendi parametreleri vardır. Mikroskobik modeller bilgisayar destekli simülasyon programlarıdır.

\section{Sonuç}

Yangın doğası itibari ile birçok tahribata ve yıkıma neden olmaktadır. İnsan canını kurtarmak ve vücut bütünlügünü muhafaza etmek yangın güvenliği konseptlerinin en birinci amacı ve ödevidir. Dolayısıyla yangın güvenliği konseptlerinin içerisinde tahliye tedbirleri ayrı bir öneme sahiptir. Tahliyeye tedbirleri teknik alt yapıya bağlı olarak yangın anında tahliye kolaylığı sunar. Bunun için yönetmeliğin ilgili bölümlerinde ve eklerinde bir kısım yasal zorunluluklar getirmiştir. Yine bir kısım uluslararası norm kuruluşları getirdikleri standartlarla tahliye işlemlerine bir çerçeve çizmeye çalışmışlardır. Bütün bu normlar geliştirilirken tahliyeye etki eden faktör göz önünde bulundurulmuştur. Tahliyeye etki eden faktörlerin elbette ki başında yangının şiddeti ve yangınla beraber yayılan isı ve duman gelmektedir. Yapısal ve teknik tedbirler genel itibari ile yayılan bu 1S1 ve dumanı baskılamak ve kaçış yollarını dizayn etmek üzere kurgulanmıştır. Ancak insan tahliye işlemine etki eden ve çok çeşitli etkileri olan bir faktör olarak karşımıza çıkmaktadır. İnsan faktörünü de kendi içerisinde bedensel, ruhsal ve biyolojik faktörler olarak sınıflandırabiliriz.

Tahliye sürelerini hesaplamak için birçok metot geliştirilmiştir. Tahliye işlemi üzerine bilimsel çalışmalar yazılmaya başladığında manuel metotlar geliştirilmiştir. Manuel metotlar hem maliyetli oluyordu hem de çok çeşitli değiş̧kenleri ilave ederek yeni deneyler yapmak güç oluyor ve zaman alıyordu. Gelişen teknolojiye bağlı olarak bilgisayar destekli birçok program geliştirildi. Geliştirilen bu programlar sayesinde bilim adamları tahliye sürelerini ona etki eden bütün faktörleri ekleyerek hesaplama imkânı buldular. Tehlikeli sınıfa tabi işletmelerin ve özellikle toplanma amaçlı bina ve tesislerin tahliyeye ilişkin yapısal ve teknik tedbirlerinin etkinliğini bilgisayar destekli programlarla ölçmeleri ileride muhtemel bir yangın anında tahliye kabiliyetlerini test etme adına önemlidir. Bu tür simülasyonlar yönetimsel tedbirler üzerinde de bir bakış açısı kazandıracak ve farkındalık oluşturacaktır.

\section{KAYNAKLAR}

[1] Schneider, U.und Lebeda, C. (2000) Baulicher Brandschutz, Stuttgart; Berlin; Köln. 
[2] Predtetschenski, W. M. und Milinski, A. I. Personenströmein Gebäuden Berechnungsmethoden für die Projektierung. Köln-Braunsfeld; 1971.

[3] Müller, G. Kriterien für Evakuierungsempfehlungen bei Chemikalienfreisetzungen, Zivilschutz-Forschung, Neue Folge Band 32, Bundesamt für Zivilschutz, Bonn; 1998.

[4] Prendke, W.-D., Schröder, H. Lexikon der Feuerwehr. Kohlhammer Verlag, Stuttgart,3. Aufl. 2005.

[5] Ruhrhofer, M. und Schweitzer, R. Beurteilung der Räumung und Evakuierung von Personen aus Gebäuden. In: Brandschutz Arbeitssicherheit Jahrbuch, Beratungsstelle für Brand- und Umweltschutz, Verlag Druckservice Muttenthaler, Petzenkirchen/Österreich, s. 104-107; 2003.

[6] Mark, R. Das Fluchtverhalten von Menschen in Extremsituationen. Brandverhütung 1/2001, S. 7-10; 2001.

[7] Sieber, G.M. Pank. vfdb-Zeitschrift Forschung und Technik im Brandschutz 2, 1986: s. 39-

41.

[8] Helbing, D.,Farkas, I. and Vicsek, T. Simulating Dynamical Features of Escape Panic, Dresden; 2000.

[9] Schneider, U. und Kirchberger, H. Evakuierungsberechnungen bei Brandereignissen mittels Ingenieurmethoden, in: "Brandschutz Jahrbuch 2006/07 Arbeitsicherheit", Petzenkirchen, s. 62 $75 ; 2007$.

[10] Linn, P. Evakuierung von Hochhäusern im Gefahrenfall -Grundlagen und Systematik,Optimierung unter Zuhilfenahme gebäudetechnischer Anlagen Bachelorarbeit im Studiengang Rettungsingenieurwesen/ Rescue Engineering, Hochschule für Angewandte Wissenschaften Hamburg Fakultät Life Sciences, Hamburg; 2012. 